\title{
The individual rehabilitation project: a model to strengthen clinical rehabilitation in health systems worldwide
}

\author{
Mauro ZAMPOLINI ${ }^{1}$, Gerold STUCKI 2, 3 *, Alessandro GIUSTINI ${ }^{4}$, Stefano NEGRINI 5, 6
}

1USL Umbria 2, Foligno Hospital, Perugia, Italy; ${ }^{2}$ Center for Rehabilitation in Global Health Systems, University of Lucerne, Lucerne, Switzerland; ${ }^{3}$ Swiss Paraplegic Research, Nottwil, Switzerland; ${ }^{4 S a n}$ Pancrazio Rehabilitation Hospital, Arco, Trento, Italy; 5 University of Brescia, Brescia, Italy; ${ }^{6}$ Don Carlo Gnocchi Foundation and IRCCS, Milan, Italy

*Corresponding author: Gerold Stucki, Swiss Paraplegic Research, Guido A. Zäch Strasse 4, 6207 Nottwil, Switzerland. E-mail: gerold.stucki@paraplegie.ch

$S^{t}$

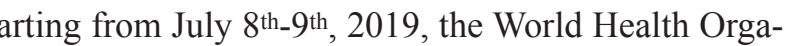
nization (WHO) held its Second Global Rehabilitation 2030 Meeting. The meeting reaffirmed rehabilitation as one of the five health strategies in light of the Astana Declaration on Primary Healthcare 2018, ${ }^{1}$ following the Declaration of Alma-Ata (now Almaty) from 1978. ${ }^{2}$ WHO's Second Global Rehabilitation 2030 Meeting highlighted functioning as the third health indicator, complementing mortality and morbidity, 3,4 and reasserted the central role of functioning for rehabilitation. ${ }^{5-7}$ Key insights from the Second Global Rehabilitation 2030 Meeting included the need for suitable approaches to strengthening rehabilitation from both the public health and the clinical perspective.

The need for strengthening rehabilitation as a public health strategy was made apparent with the data from the Global Burden of Disease project ${ }^{8}$ that underscored the large number of potential beneficiaries of rehabilitation across a wide range of health conditions and over the life course. ${ }^{9}$ To ensure that all potential beneficiaries of rehabilitation worldwide have access to high quality rehabilitation services under Universal Health Coverage schemes, WHO launched the Guide for Action for policy and programming at the country level ${ }^{10}$ and embarked on the development of a research agenda for health policy and systems research in collaboration with WHO's Alliance for Health Policy and Systems Research. ${ }^{11}$

To strengthen rehabilitation from the clinical perspective, WHO will provide member states with a Package of Rehabilitation Interventions in collaboration with Co- chrane Rehabilitation..$^{9,12}$ Long recognized as fundamental in rehabilitation, functioning is an underlying element that threads the development of the Package of Rehabilitation Interventions. ${ }^{13-15}$ Functioning, operationalized by the International Classification of Functioning, Disability and Health (ICF), ${ }^{16}$ plays a role in identifying the interventions to include in the Package of Rehabilitation Interventions as well as intervention gaps, in reporting outcomes related to interventions, and in describing human and technical resources requirements in specific interventions. ${ }^{12}$

The Second Global Rehabilitation 2030 Meeting provided the platform for discussions on how to make best use of both the Guide for Action and the Package of Rehabilitation Interventions towards advancing the Rehabilitation 2030 agenda. In light of these discussions we aim to highlight in this editorial the potential of the ICF-based Individual Rehabilitation Project developed in Italy to serve as a model for strengthening clinical rehabilitation in countries worldwide.

\section{The Individual Rehabilitation Project developed in Italy}

In 1990 the Italian Society of Physical and Rehabilitation Medicine (SIMFER) started an internal discussion to define a methodology that rehabilitation team members could employ for developing the rehabilitation project. During these discussions, SIMFER considered the experiences of the international rehabilitation medicine community, e.g. American Academy of Physical Medicine and 


\section{COPYRIGHT $^{\circledR} 2020$ EDIZIONI MINERVA MEDICA}

Rehabilitation. Subsequently, a commission of the Ministry of Health was established under the coordination of Prof. Nino Basaglia to develop the guidelines on rehabilitation for Italy. ${ }^{17}$

In 1998, the Italian Ministry of Health published the guidelines on rehabilitation (referred to as "guidelines" from now on) to define the methods, procedures, and facilities in rehabilitation. ${ }^{18}$ An important feature of the guidelines was the introduction of the Progetto Riabilitativo Individuale, or, in English, the Individual Rehabilitation Project (IRP). The guidelines define IRP as "the set of propositions, elaborated by the rehabilitation team, coordinated by the medical doctor specialist." The IRP ought to take into account the needs and desired outcomes of the patient (and/or his/her family, when appropriate), his/her impairments, activity limitations, and restrictions of participation, as well as the environmental and personal factors. Desired outcomes reflect the expectations and priorities of the patient and his/her family. The IRP comprises short, intermediate and long-term goals, the expected timeframe for achieving these goals, the interventions, and the requirements necessary to achieve the desired results.

The 1998 guidelines called for the implementation of the IRP in practice to be determined at a regional level. In most regions in Italy, establishing an IRP is mandatory for rehabilitation interventions to be performed. ${ }^{19}$

The 1998 guidelines were the first attempt to bring structure to rehabilitation care and to establish a national rehabilitation strategy. However, these initial guidelines were implemented inconsistently across regions. Furthermore, standardization of terms and definitions was warranted. For example, a specific rehabilitation service provided had different names in different regions while a service with the same name was provided with different interventions across Italy. ${ }^{20}$ When the guidelines were launched in 1998, ICF16 was still in development. In response to the inconsistent implementation of the guidelines across Italy, the Italian Ministry of Health updated the guidelines in 2011. The updated guidelines recognized the ICF as a unifying model to analyze the complexity of the patient's health status, and promoted the creation of a patient-individualized functioning profile. 20

\section{How the IRP can serve as a model for clinical rehabilitation}

The full form of the acronym IRP, i.e. 'Individual Rehabilitation Project' is meaningful in itself. The term 'in- dividual' denotes the clinical context in clear distinction from the context of policy and service provision (in fact, for the latter, the 1998 Guidelines propose also a "Structure Rehabilitation Project". 15 The term 'project' implies an episode with a start and an end centered around an objective and involving a plan, its execution and evaluation.

The IRP developed in Italy reflects the reality described in the White Book of Physical and Rehabilitation Medicine in Europe, 13, 15, 21 and it embodies the "Rehab-Cycle," 22,23 specifically that rehabilitation is more than a set of interventions. Rehabilitation is best described as an intricate intervention scheme provided by a multi-professional team in a rehabilitation process. ${ }^{24-26}$ This process involves an assessment of functioning limitations, environmental barriers and psychosocial resources, the setting of goals and identification of intervention targets at the level of functioning, psychosocial resources and environment, the assignment of tasks to members of the interdisciplinary rehabilitation team, the conduct and monitoring of interventions, the evaluation of intervention outcomes and possibly the initiation of a new Rehab-Cycle. This process relies on the ICF as a reference system as described in a series of methodological notes published by this journal. ${ }^{27-29}$

Considering the multi-faceted and comprehensive rehabilitation process described above, the IRP can serve as a model for strengthening clinical rehabilitation in health systems worldwide. In terms of WHO's Package of Rehabilitation Interventions, the goal-setting and monitoring features of the IRP can support the reporting of outcomes related to interventions. The intervention assignment feature facilitates the identification of interventions redundancies and gaps, and brings transparency to the required human and technical resources.

At the European level, the Physical and Rehabilitation Medicine Section and Board of the European Union of Medical Specialists (UEMS-PRM) is currently developing a model of the IRP that can be tailored across various rehabilitation types across the continuum of care and along the life course..$^{30}$ For the development of the IRP, the UEMS-PRM Section and Board will apply an iterative consensus process, including Delphi surveys across its member societies, to identify the key components of the IRP that represent the reality of clinical rehabilitation in Europe. Through a similar methodological approach, it would seem possible to develop applications of the IRP suitable for settings in low-, middle- and high-income countries, as well as specific situations across rehabilita- 


\section{COPYRIGHT $^{(\odot)} 2020$ EDIZIONI MINERVA MEDICA}

tion services types ${ }^{30-32}$ and rehabilitation in emergency and disaster relief.

In conclusion, we see the unique opportunity to learn from the Italian experience in developing, implementing and continuously refining the IRP. Moreover, countries can rely on methods developed in the context of health policy and systems research including "scaling up" and the "learning health system." 33,34

\section{References}

1. World Health Organization and United Nations Children's Fund Declaration of Astana - Global Conference on Primary Health Care; 2018 [Internet]. Available from: www.who.int/docs/default-source/ primary-health/declaration/gcphc-declaration.pdf [cited 2019, Dec 13].

2. World Health Organization and United Nations Children's Fund. Declaration of Alma-Ata. International Conference on Primary Health Care; 1978 [Internet]. Available from: www.who.int/publications/almaata declaration_en.pdf [cited 2019, Dec 13].

3. Cieza A. Rehabilitation the Health Strategy of the 21st Century, Really? Arch Phys Med Rehabil 2019;100:2212-4.

4. Stucki G, Bickenbach J. Functioning: the third health indicator in the health system and the key indicator for rehabilitation. Eur J Phys Rehabil Med 2017;53:134-8.

5. World Health Organization. Rehabilitation. 2030: A call for action. Rehabilitation: key for health in the 21st century. Geneva: World Health Organization; 2017. p. 1-6.

6. Stucki G, Bickenbach J, Melvin J. Strengthening Rehabilitation in Health Systems Worldwide by Integrating Information on Functioning in National Health Information Systems. Am J Phys Med Rehabil 2017;96:677-81.

7. Negrini S, Kiekens C. Functioning is becoming a global outcome and health indicator for medicine: does this strengthen or weaken its role of main rehabilitation unifying narrative? Eur J Phys Rehabil Med 2019;55:539-41.

8. GBD 2016 Disease and Injury Incidence and Prevalence Collaborators. Global, regional, and national incidence, prevalence, and years lived with disability for 328 diseases and injuries for 195 countries, 1990-2016: a systematic analysis for the Global Burden of Disease Study 2016. Lancet 2017;390:1211-59.

9. Negrini S, Kiekens C, Heinemann AW, Özçakar L, Frontera WR. Prioritising people with disabilities implies furthering rehabilitation. Lancet 2019. [Epub ahead of print]

10. World Health Organization. Rehabilitation in Health Systems: Guide for action; 2019 [Internet]. Available from: www.who.int/rehabilitation/ rehabilitation-guide-for-action/en/ [cited 2019, Dec 13].

11. World Health Organization. Alliance for Health Policy and Systems Research; 2019 [Internet]. Available from: www.who.int/rehabilitation/ rehab-2030-2nd-meeting/en/ [cited 2019, Dec 13].

12. Rauch A, Negrini S, Cieza A. Toward Strengthening Rehabilitation in Health Systems: Methods Used to Develop a WHO Package of Rehabilitation Interventions. Arch Phys Med Rehabil 2019;100:2205-11.

13. Meyer T, Gutenbrunner C, Bickenbach J, Cieza A, Melvin J, Stucki G. Towards a conceptual description of rehabilitation as a health strategy. J Rehabil Med 2011;43:765-9.

14. Krug E, Cieza A. Strengthening health systems to provide rehabilitation services. Bull World Health Organ 2017;95:167.

15. European Physical and Rehabilitation Medicine Bodies Alliance. White Book on Physical and Rehabilitation Medicine in Europe. Intro- ductions, Executive Summary, and Methodology. Eur J Phys Rehabil Med 2018;54:125-55.

16. World Health Organization. International Classification of Functioning, Disability and Health. Geneva: World Health Organization; 2001.

17. Italian Society of Physical Medicine and Rehabilitation. Guidelines for rehabilitation services in Italy. Eur Med Phys 2005;41:95-109.

18. Italian Ministry of Health. Linee-guida del Ministro della sanità per le attività di riabilitazione. Gazzetta Ufficiale 30 May 1998 (n. 124).

19. Negrini S, Giustini A, Saraceni V, Zampolini M. Organization of physical and rehabilitation medicine in Italy: new ways toward developing our specialty. PM R 2013;5:462-8.

20. Italian Health Ministry. Rehabilitation national plan: an Italian act. Eur J Phys Rehabil Med 2011;47:621-38.

21. Gutenbrunner C, Meyer T, Melvin J, Stucki G. Towards a conceptual description of Physical and Rehabilitation Medicine. J Rehabil Med 2011;43:760-4

22. Rauch A, Cieza A, Stucki G. How to apply the International Classification of Functioning, Disability and Health (ICF) for rehabilitation management in clinical practice. Eur J Phys Rehabil Med 2008;44:329-42.

23. Stucki G, Bickenbach J, Selb M, Melvin J. Chapter 9: The International Classification of Functioning, Disability and Health. In: Frontera W, DeLisa J, Gans B, Robinson L, Bockeneck W, Chase J, editors. DeLisa's Physical Medicine and Rehabilitation: Principles and Practice. Sixth edition. Philadelphia: Wolters Kluwer; 2019. p. 208-26.

24. European Physical and Rehabilitation Medicine Bodies Alliance. White Book on Physical and Rehabilitation Medicine (PRM) in Europe. Chapter 3. A primary medical specialty: the fundamentals of PRM. Eur J Phys Rehabil Med 2018;54:177-85.

25. European Physical and Rehabilitation Medicine Bodies Alliance. White Book on Physical and Rehabilitation Medicine (PRM) in Europe. Chapter 6. Knowledge and skills of PRM physicians. Eur J Phys Rehabil Med 2018;54:214-29.

26. European Physical and Rehabilitation Medicine Bodies Alliance. White Book on Physical and Rehabilitation Medicine (PRM) in Europe. Chapter 7. The clinical field of competence: PRM in practice. Eur J Phys Rehabil Med 2018;54:230-60.

27. Stucki G, Bickenbach J, Negrini S. Methodological notes on applying the International Classification of Functioning, Disability and Health in rehabilitation. Eur J Phys Rehabil Med 2017;53:132-3.

28. Stucki G, Prodinger B, Bickenbach J. Four steps to follow when documenting functioning with the International Classification of Functioning, Disability and Health. Eur J Phys Rehabil Med 2017;53:144-9.

29. Prodinger B, Tennant A, Stucki G. Standardized reporting of functioning information on ICF-based common metrics. Eur J Phys Rehabil Med 2018;54:110-7.

30. Stucki G, Zampolini M, Selb M, Ceravolo MG, Delargy M, Varela Donoso E, et al.; Study Group European Framework of Rehabilitation Service Types. European Framework of Rehabilitation Services Types: the perspective of the Physical and Rehabilitation Medicine Section and Board of the European Union of Medical Specialists. Eur J Phys Rehabil Med 2019;55:411-7.

31. Selb M, Zampolini M, Delargy M, Kiekens C, Stucki G; Study Group CLINICAL ASSESSMENT SCHEDULE. Specifying clinical assessment schedules for the European framework of rehabilitation service types: the perspective of the physical and rehabilitation medicine section and board of the European Union of medical specialists. Eur J Phys Rehabil Med 2019. [Epub ahead of print]

32. Engkasan JP, Stucki G, Ali S, Yusof YM, Hussain H, Latif LA. Implementation of Clinical Quality Management for Rehabilitation in Malaysia. J Rehabil Med 2018;50:346-57.

33. de Savigny D, Taghreed A. Systems thinking for health systems 


\section{COPYRIGHT $^{(\odot)} 2020$ EDIZIONI MINERVA MEDICA}

ZAMPOLINI

INDIVIDUAL REHABILITATION PROJECT

strengthening. Alliance for Health Policy and Systems Research, World Health Organization; 2009 [Internet]. Available from: www.who.int/alliance-hpsr/resources/9789241563895/en/ [cited 2019, Dec 13].
34. Stucki G, Bickenbach J. The Implementation Challenge and the Learning Health System for SCI Initiative. Am J Phys Med Rehabil 2017;96(Suppl 1):S55-60.

Conflicts of interest.- The authors certify that there is no conflict of interest with any financial organization regarding the material discussed in the manuscript.

Acknowledgements.-The authors would like to thank members of the SIMFER, Melissa Selb for her input from the ICF perspective, and Cristiana Baffone for her scientific coordination and support in the preparation of the manuscript.

Article first published online: December 3, 2019. - Manuscript accepted: November 28, 2019. - Manuscript received: November 26, 2019.

(Cite this article as: Zampolini M, Stucki G, Giustini A, Negrini S. The individual rehabilitation project: a model to strengthen clinical rehabilitation in health systems worldwide. Eur J Phys Rehabil Med 2020;56:1-4. DOI: 10.23736/S1973-9087.19.06110-0) 